\title{
NON-LINEAR SOIL BEHAVIOR ON FREIGHT VS PASSENGER LINES
}

\author{
KAITAI DONG ${ }^{1}$, DAVID P. CONNOLLY ${ }^{2}$, OMAR LAGHROUCHE $^{1}$, \\ PETER K. WOODWARD ${ }^{2} \&$ PEDRO ALVES COSTA ${ }^{3}$ \\ ${ }^{1}$ Heriot Watt University, UK \\ ${ }^{2}$ University of Leeds, UK \\ ${ }^{3}$ University of Porto, Portugal
}

\begin{abstract}
Upgrading existing passenger-only railway lines to carry freight traffic is becoming increasingly desirable. This is challenging because freight trains have larger axle loads and thus can have a negative effect on track longevity, particularly on ballasted lines supported by sub-optimal ground conditions. These additional loads can cause large subgrade strains resulting in non-linear behaviour, which should be considered before permitting freight vehicles on passenger routes. To do so requires the modelling of non-linear soil behaviour which is challenging. Therefore, this paper presents a solution in the form of an equivalent non-linear, thin layer element soil model, coupled to an analytical track model. The model has low computational demand and can adjust subgrade stiffness depending upon strain levels. Therefore, it is well suited to computing track response induced by freight trains. This paper validates the model and then uses it to compare the differences between the response of a ballasted line to freight and passenger vehicles.

Keywords: railway freight, railroad, non-linear soil.
\end{abstract}

\section{INTRODUCTION}

On some railway lines it can be necessary to combine freight and passenger trains on tracks that were only designed for passenger vehicles. These lines were never planned for freight traffic, and as such, the effect of increased axle loads on track behavior is unclear.

To better understand track behaviour due to different types of loading, a range of numerical modelling approaches have been suggested. These include analytical models [1][3], semi-analytical models [4]-[9]. There are also numerical models: 2.5D models [10]-[15] and fully $3 \mathrm{D}$ models using finite element (FE) and possibly boundary element (BE) theories [16]-[22].

In-situ testing can be financially expensive [23], meaning it can be more cost effective to try to understand track performance and ground response from freight trains using mathematical models. For freight traffic, the dominant vibration frequency components are in the range 4-30 Hz, so Jones and Block [24] proposed a track response model combined with transfer functions from sleeper to ground.

When modelling railway track response, linear elastic models of the soil are commonly used, thus assuming strain levels are small. However, heavy loads and high speeds can result in high strain levels and thus a non-linear soil response [5], [12]. Some researchers have proposed manually reducing soil stiffness to account for non-linearity [5], [6]. Alternatively, an equivalent non-linear approach can be used where the Young's modulus is automatically adjusted based on the maximum effective octahedral shear strain at all points in the soil mesh. Then it can be updated until convergence [12].

Considering that non-linear ground response can greatly effect track response, this paper outlines an efficient semi-analytical approach for modelling non-linear soil effects in the presence of freight traffic. The track response is simulated using a 1D analytical approach 
and the soil is simulated using the thin-layer method. To facilitate non-linear soil response, the soil stiffness is computed based upon strain levels in an iterative manner.

\section{NUMERICAL MODEL DEVELOPMENT}

Freight trains carry heavy axle loads which can potentially cause large strains within the track's supporting subgrade. This results in non-linear soil behaviour, and thus reduced support stiffness. Modelling non-linear soil behaviour in the time domain is typically computationally intensive, so to reduce computational requirements, a frequency domain, thin-layer finite element model was developed, and combined with an equivalent non-linear procedure. This soil model was then coupled with a track model.

\subsection{Track model}

For all simulations a ballasted track was considered with rail, railpad, sleeper and ballast elements. Vertical wave propagation was permitted and the track was coupled to the thinlayer ground model using a spring defined in the frequency-wavenumber domain

$$
\left[\begin{array}{ccc}
E I_{r} k_{1}^{4}+k_{p}^{*}-\omega^{2} m_{r} & -k_{p}^{*} & 0 \\
-k_{p}^{*} & k_{p}^{*}+\frac{2 \omega E_{b}^{*} b \alpha}{\tan \left(\frac{\omega h}{c_{p}}\right) c_{p}}-\omega^{2} m_{s} & \frac{-2 \omega E_{b}^{*} b \alpha}{\sin \left(\frac{\omega h}{c_{p}}\right) c_{p}} \\
0 & \frac{-2 \omega E_{b}^{*} b \alpha}{\sin \left(\frac{\omega h}{c_{p}}\right) c_{p}} & \frac{2 \omega E_{b}^{*} b \alpha}{\tan \left(\frac{\omega h}{c_{p}}\right) c_{p}}+k_{e q}
\end{array}\right]\left\{\begin{array}{c}
\tilde{u}_{r}\left(k_{1}, \omega\right) \\
\tilde{u}_{s}\left(k_{1}, \omega\right) \\
\tilde{u}_{b b}\left(k_{1}, \omega\right)
\end{array}\right\}=\left\{\begin{array}{c}
\tilde{P}\left(k_{1}, \omega\right) \\
0 \\
0
\end{array}\right\} .
$$

In this equation, $\mathrm{EI}_{\mathrm{r}}$ is the bending stiffness of the rail; $\mathrm{m}_{\mathrm{r}}$ is the mass of rails per meter; $\mathrm{m}_{\mathrm{s}}$ is the equivalent distributed mass of sleepers; $\mathrm{k}_{\mathrm{p}}{ }^{*}$ is the complex stiffness of the railpad; $\mathrm{k}_{\mathrm{eq}}$ is the equivalent stiffness of the ground; $\mathrm{E}_{\mathrm{b}}{ }^{*}$ is the Young's modulus of the ballast; $\mathrm{C}_{\mathrm{p}}$ is the compression wave speed in the ballast; $h$ is the ballast layer height; $\alpha$ is the adimensional parameter, taken as 0.5 ; $b$ is the half-width of the track.

The ballasted track model was coupled to the soil using the complex equivalent stiffness of the ground $\mathrm{k}_{\mathrm{eq}}$. The ratio between the force and mean deflection at the track-soil connection was used to compute the equivalent stiffness [25]. This stiffness was computed as:

$$
\tilde{k}_{e q}\left(k_{1}, \omega\right)=\frac{2 \pi}{\int_{-\infty}^{+\infty} \tilde{u}_{z Z}^{G}\left(k_{1}, k_{2}, 0, \omega\right) C_{t g} d k_{2}},
$$

where $\mathrm{u}_{\mathrm{zz}}$ is the Green's function of vertical displacement of the ground in the wavenumberfrequency domain, and $\mathrm{k}_{1}$ and $\mathrm{k}_{2}$ are the Fourier images of coordinate $\mathrm{x}$ and $\mathrm{y}$, respectively. The Green function was computed using the Haskell-Thompson approach [4].

\subsection{Ground model}

The ground was modelled using the Thin-Layer Method (TLM). This involved discretising the medium into infinitely horizontal layers (Fig. 1).

The key modelling details are:

- The thickness of the thin layers was based on the maximum wavenumber, $\mathrm{h}=$ wavelength $/ 8=2 \pi / 8 \mathrm{k}_{\max }$ 


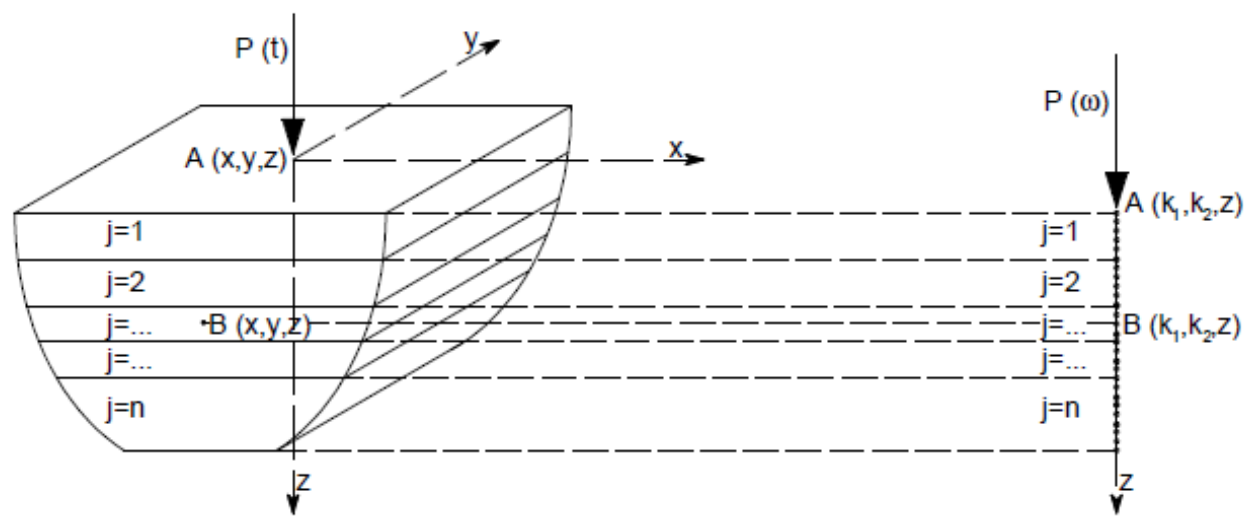

Figure 1: Schematic diagram of the TLM modelling process.

- For high accuracy stress-strain computation, quadratic elements were used

- Once the displacements were calculated for individual nodes, strains and stresses were computed using:

$$
\begin{gathered}
\{\boldsymbol{\varepsilon}\}=[\mathbf{B}]\{\mathbf{U}\}, \\
\{\boldsymbol{\sigma}\}=[\mathbf{D}]\{\boldsymbol{\varepsilon}\}=[\mathbf{D}][\mathbf{B}]\{\mathbf{U}\},
\end{gathered}
$$

where $[\mathbf{B}]=\left[\begin{array}{lll}\mathbf{B}_{1} & \mathbf{B}_{2} & \mathbf{B}_{3}\end{array}\right]$ and

$$
\begin{gathered}
{\left[\mathbf{B}_{i}\right]=\left(\begin{array}{ccc}
i k_{1} N_{i} & 0 & 0 \\
0 & i k_{2} N_{i} & 0 \\
0 & 0 & \frac{\partial N_{i}}{\partial z} \\
i k_{2} N_{i} & i k_{1} N_{i} & 0 \\
0 & \frac{\partial N_{i}}{\partial z} & i k_{2} N_{i} \\
\frac{\partial N_{i}}{\partial z} & 0 & i k_{1} N_{i}
\end{array}\right)} \\
N_{1}(\xi)=\frac{1}{2} \xi^{2}-\frac{1}{2} \xi \\
N_{2}(\xi)=1-\xi^{2} \\
N_{3}(\xi)=\frac{1}{2} \xi^{2}+\frac{1}{2} \xi
\end{gathered}
$$

- After computing the result in the wavenumber-frequency domain, they were converted back into the time-space domain using the inverse Fourier Transform 


\subsection{Equivalent non-linear model}

To simulate non-linearity, a non-linear equivalent, iterative stiffness updating procedure was used. Because the model was computed in the frequency domain [27] and computationally efficient, it was well-suited to an interactive updating approach. It was as follows:

1. Low strain $\left(\mathrm{G}_{0}\right)$ material properties were assumed for the entire ground model

2. Compute strains in all directions and for all elements, and thus calculate the resulting maximum effective octahedral shear strains

3. Combine the octahedral strains with stiffness degradation curves (Fig. 2), to calculate new stiffness values for all elements

4. Repeat the procedure for material damping

5. Repeat steps $2-4$ until convergence

\section{MODEL VALIDATION}

The model was based upon the accurate calculate of stresses and strains within the soil, to allow for non-linear equivalent computation. Therefore, it was vital that these were being accurately calculated. To validate this, results were compared against the case of a beam on a half space excited by a moving point load [26], [27].

\subsection{Model description}

A train-embankment-ground model was considered with a Euler beam resting on the surface an infinitely deep homogenous ground. It was subjected to a concentrated moving point load acting at the centre of the beam (Fig. 3). The half-space was modelled using the TLM model and the compatibility between the beam and soil was achieved using the equivalent stiffness formula described previously. Stresses were calculated at $2 \mathrm{~m}$ depth below the soil surface.

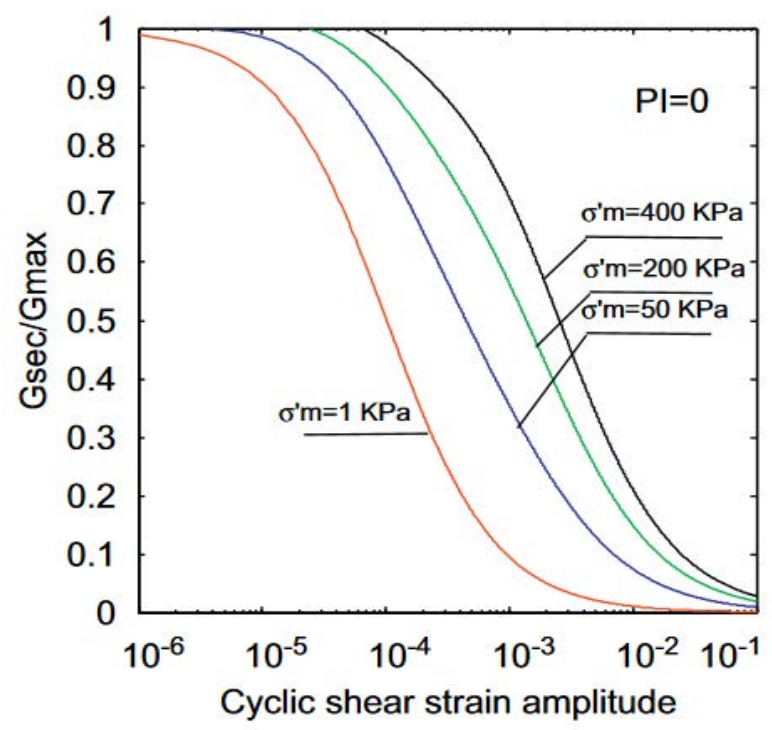

Figure 2: Stiffness reduction curves used for non-linearity. (Source: Alves Costa et al. [12].) 


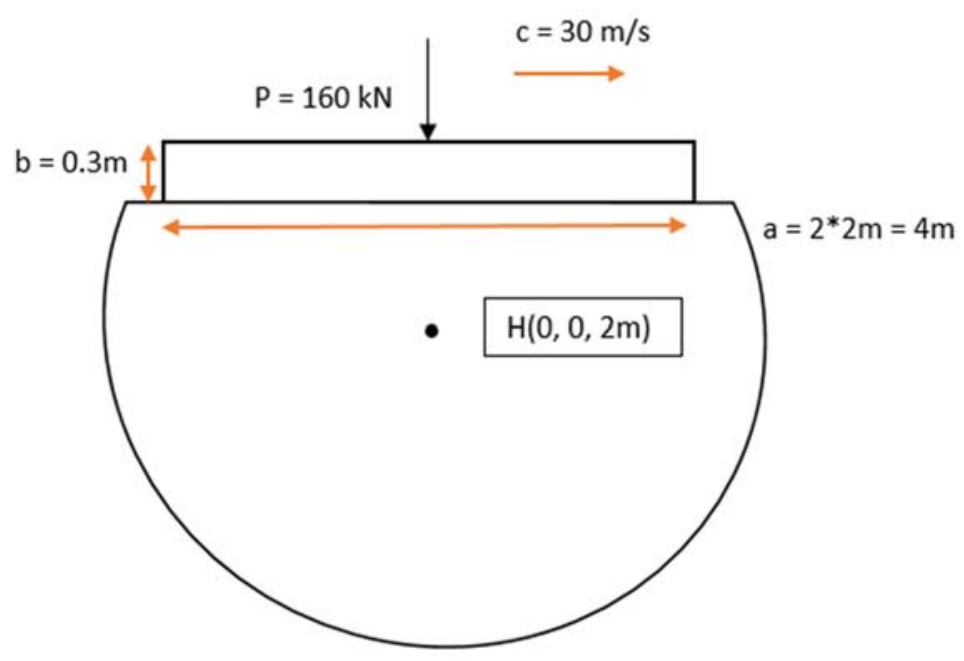

Figure 3: Schematic of validation case.

The beam and soil material properties are shown in Table 1 and Table 2 respectively. The load speed was $30 \mathrm{~m} / \mathrm{s}$ with an amplitude of $160 \mathrm{kN}$.

\subsection{Simulation result}

The vertically acting point load meant that shear stress $\tau_{\mathrm{xy}}$ and $\tau_{\mathrm{yz}}$, at the measurement location were zero. Therefore, the normal stresses $\sigma_{\mathrm{xx}}, \sigma_{\mathrm{yy}}, \sigma_{\mathrm{zz}}$, and one shear stress $\tau_{\mathrm{xz}}\left(=\tau_{\mathrm{zx}}\right)$ was analysed.

Fig. 4 reveals strong agreement between the model and published case for all dynamic stresses. Therefore, it was concluded that the TLM railway model was capable of accurately calculating ground response.

Table 1: Properties of the embankment.

\begin{tabular}{|c|c|c|c|c|c|}
\hline $\begin{array}{c}\text { Density } \\
\left(\mathrm{kg} / \mathrm{m}^{3}\right)\end{array}$ & $\begin{array}{c}\text { Young's } \\
\text { modulus (MPa) }\end{array}$ & $\begin{array}{c}\text { Width } \\
(\mathrm{m})\end{array}$ & $\begin{array}{c}\text { Height } \\
(\mathrm{m})\end{array}$ & $\begin{array}{c}\text { Mass } \\
(\mathrm{kg})\end{array}$ & $\begin{array}{c}\text { Second moment } \\
\text { of area }\left(\mathrm{m}^{4}\right)\end{array}$ \\
\hline 1900 & 30000 & 4 & 0.3 & 2280 & 0.009 \\
\hline
\end{tabular}

Table 2: Sil properties.

\begin{tabular}{|c|c|c|c|}
\hline $\begin{array}{c}\text { Shear modulus } \\
(\mathrm{MPa})\end{array}$ & Poisson's ratio & Density $\left(\mathrm{kg} / \mathrm{m}^{3}\right)$ & $\begin{array}{c}\text { Shear wave } \\
\text { speed }(\mathrm{m} / \mathrm{s})\end{array}$ \\
\hline 10 & 0.45 & 1800 & 74.54 \\
\hline
\end{tabular}




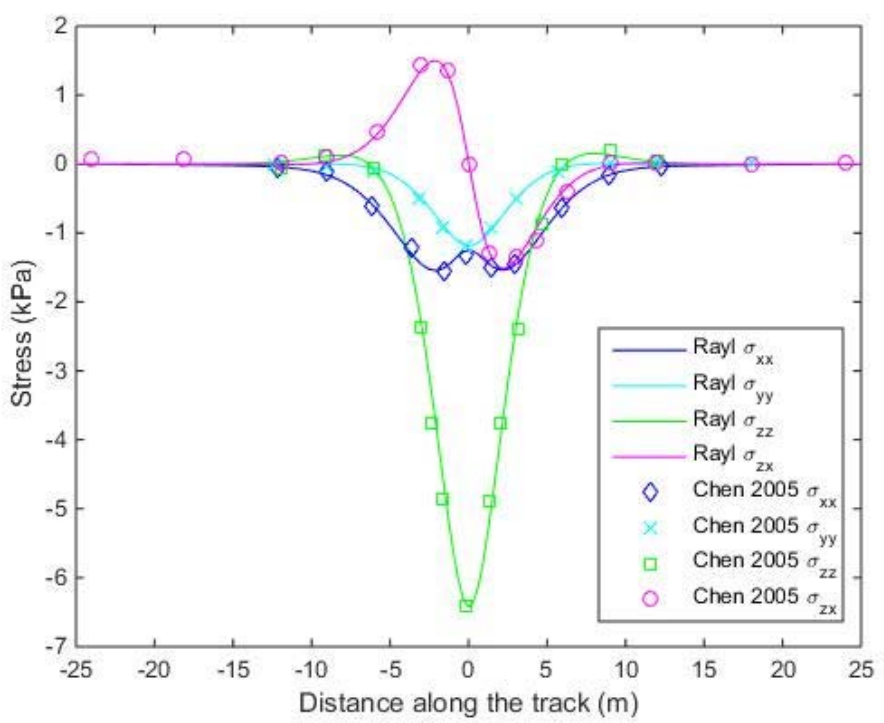

Figure 4: Dynamic stresses at $2 \mathrm{~m}$ from soil surface.

\section{ANALYSIS AND RESULTS}

Models were run to compare the response of a 25-tonne freight axle load to a 17-tonne passenger vehicle. A ballasted track was considered with the following properties: $\mathrm{m}_{\mathrm{r}}=120$ $\mathrm{kg} / \mathrm{m}, \mathrm{m}_{\mathrm{s}}=490 \mathrm{~kg} / \mathrm{m}, \mathrm{k}_{\mathrm{p}}{ }^{*}=5 \times 10^{8} \mathrm{~N} / \mathrm{m}^{2}, \mathrm{E}_{\mathrm{b}}{ }^{*}=125 \mathrm{MPa}, \mathrm{h}=0.35 \mathrm{~m}, \mathrm{~b}=2.5 \mathrm{~m}$. The soil was modelled as a homogenous half-space with the following properties: density $=2000 \mathrm{~kg} / \mathrm{m}^{3}$, Young's modulus $=25 \mathrm{MPa}$, Poisson's ratio $=0.35$, damping $=0.03$. The non-linear stiffness reduction curve was the same as shown earlier. The passenger and freight train speeds were $26 \mathrm{~m} / \mathrm{s}$.

Fig. 5(a) shows the relationship between the strain level and the depth below ground level. The maximum strain level was found approximately $1 \mathrm{~m}$ from the track-soil interface and reduced rapidly as depth increased. Also, Fig. 5(b) shows the effect of strain levels on soil stiffness. By the second iteration, the soil was only at $67 \%$ of its low-strain stiffness value and by the final iteration, it was $59 \%$.

The Young's modulus for different depths, for different iterations is shown in Fig. 6(a). For iteration 1, the stiffness does not change with depth because this is the original $25 \mathrm{MPa}$ value. After strain updating though, there are large reductions with depth, particularly near the soil surface. For the linear responses, for the passenger train, track displacements were $3.7 \mathrm{~mm}$, however for the freight train, they were $5.5 \mathrm{~mm}$. Then, after considering nonlinearity, the displacements were 5.7 and $10 \mathrm{~mm}$ respectively.

Therefore, it was found that considering the non-linear nature of the soil had a very significant effect on track-ground response, and that if traditional linear was used it would significantly underestimate rail deflections. Increased displacements would lead to more frequent loss of track geometry and thus require more frequent tamping. Finally, it is also noted that dynamic effects become more noticeable when the soil stiffness reduces, with the final iteration displacements being less symmetric than the initial iteration. 


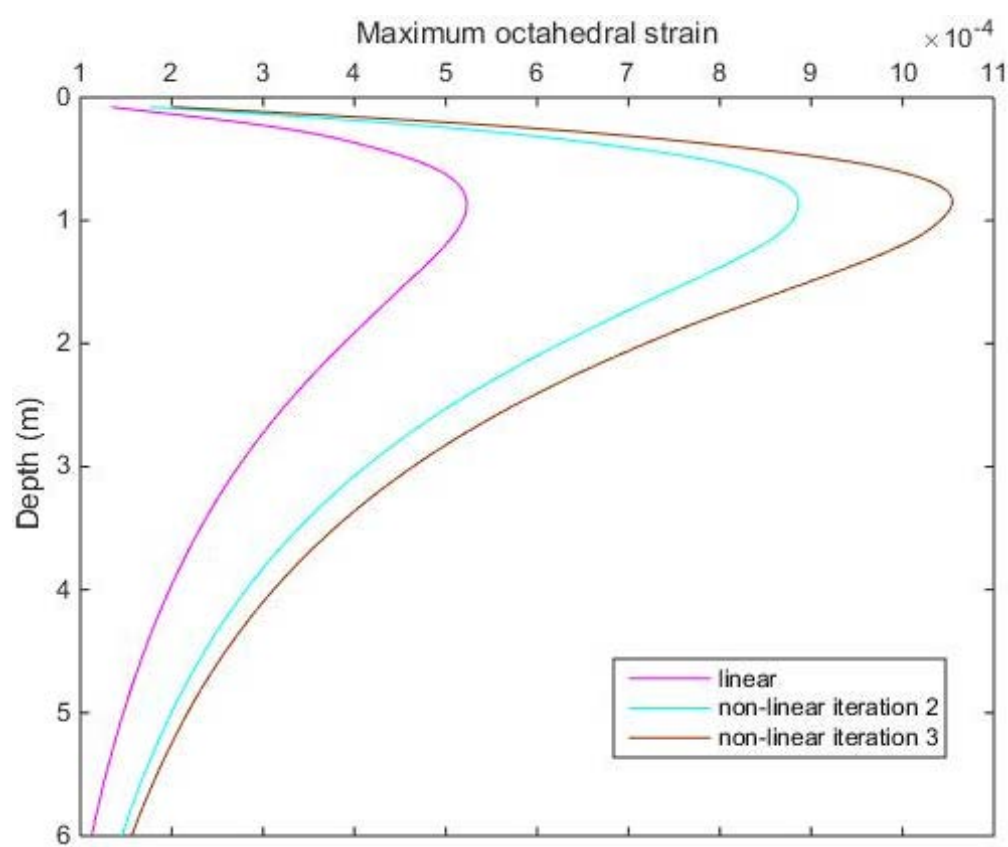

(a)

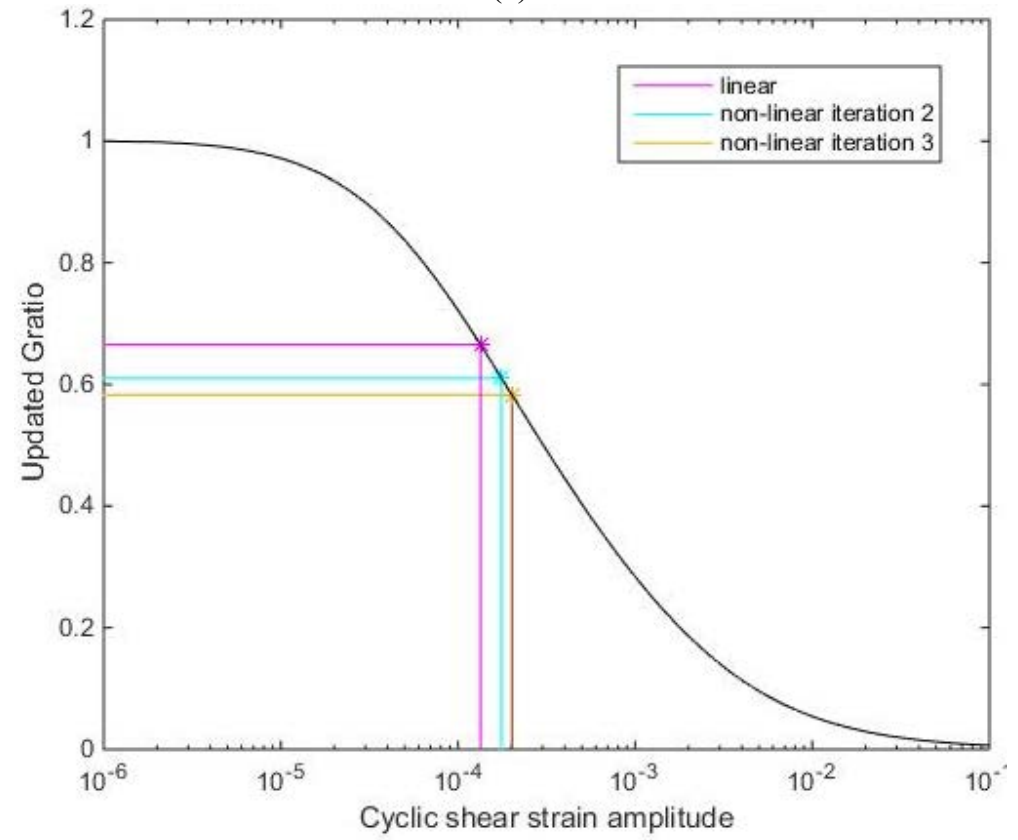

(b)

Figure 5: (a) Strain vs depth from soil surface; (b) Stiffness degradation curve with iterations shown. 


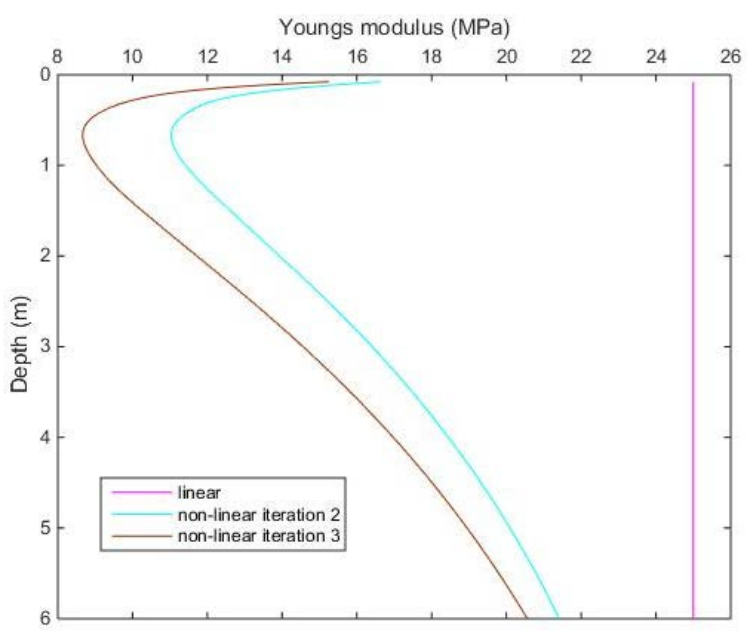

(a)

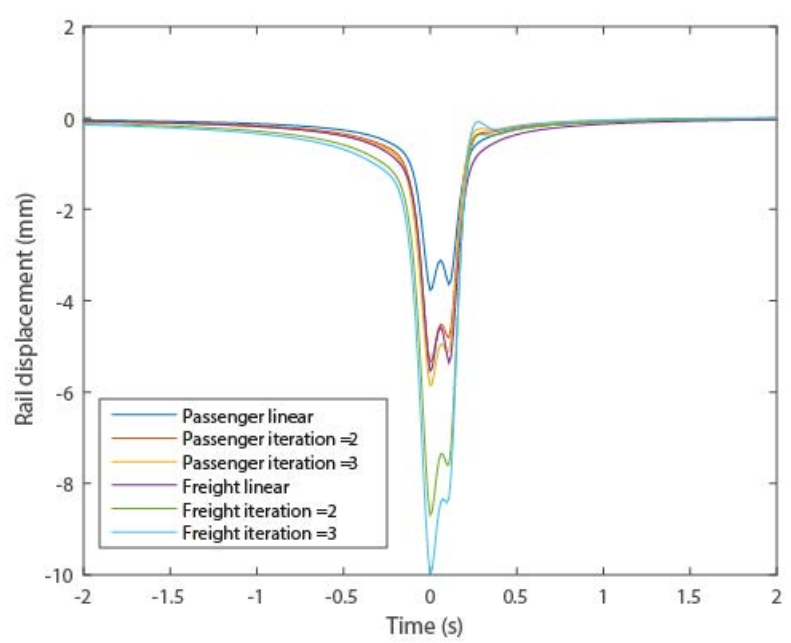

(b)

Figure 6: (a) Young's modulus reduction with depth; (b) Track displacements.

\section{CONCLUSIONS}

Upgrading existing passenger-only railway lines to carry freight traffic is becoming increasingly desirable. This is challenging because freight trains have larger axle loads and thus can have a negative effect on track longevity, particularly on ballasted lines supported by sub-optimal ground conditions. These additional loads can cause large subgrade strains resulting in non-linear behaviour, which should be considered before permitting freight vehicles on passenger routes. To do so requires the modelling of non-linear soil behaviour which is challenging. Therefore this paper presented a method to model non-linear track-soil behaviour in the frequency domain. It was used to investigate the difference between 
potential displacement levels. It was found that using linear analysis can significantly underestimate response.

\section{REFERENCES}

[1] Krylov, V.V., Generation of ground vibrations by superfast trains. Applied Acoustics, 44(2), pp. 149-164, 1995.

[2] Degrande, G. \& Lombaert, G., An efficient formulation of Krylov's prediction model for train induced vibrations based on the dynamic reciprocity theorem. The Journal of the Acoustical Society of America, 110(3), pp. 1379-1390, 2011.

[3] Takemiya, H. \& Bian, X., Substructure simulation of inhomogeneous track and layered ground dynamic interaction under train passage. Journal of Engineering Mechanics, 131(7), pp. 699-711, 2005.

[4] Sheng, X., Jones, C.J.C. \& Petyt, M., Ground vibration generated by a harmonic load acting on a railway track. Journal of Sound and Vibration, 225(1), pp. 3-28, 1999.

[5] Madshus, C. \& Kaynia, A.M., High-speed railway lines on soft ground: Dynamic behaviour at critical train speed. Journal of Sound and Vibration, 231(3), pp. 689-701, 2000.

[6] Kaynia, A. M., Madshus, C. \& Zackrisson, P., Ground vibration from high-speed trains: Prediction and countermeasure. Journal of Geotechnical and Geoenvironmental Engineering, 126(IGVC), pp. 531-537, 2000.

[7] Sheng, X., Jones, C.J.C. \& Thompson, D.J., A comparison of a theoretical model for quasi-statically and dynamically induced environmental vibration from trains with measurements. Journal of Sound and Vibration, 267(3), pp. 621-635, 2003.

[8] Mezher, S.B., Connolly, D.P., Woodward, P.K., Laghrouche, O., Pombo, J. \& Costa, P.A., Railway critical velocity - Analytical prediction and analysis. Transportation Geotechnics, 6(October), pp. 84-96, 2016

[9] Triepaischajonsak, N. \& Thompson, D.J., A hybrid modelling approach for predicting ground vibration from trains. Journal of Sound and Vibration, 335, pp. 147-173, 2015.

[10] Yang, Y.B., Hung, H.H. \& Chang, D.W., Train-induced wave propagation in layered soils using finite/infinite element simulation. Soil Dynamics and Earthquake Engineering, 23(4), pp. 263-278, 2003.

[11] Alves Costa, P., Vibrações Do Sistema Via-Maciço Induzidas Por Tráfego Ferroviário. Modelação Numérica E Validação Experimental, 2011.

[12] Alves Costa, P., Calcada, R., Couto Marques, J. \& Silva Cardoso, A., A 2.5D finite element model for simulation of unbounded domains under dynamic loading. Numerical Methods in Geotechnical Engineering, pp. 397-404, 2012.

[13] Galvín, P., François, S., Schevenels, M., Bongini, E., Lombaert, G. \& Degrande, G., A 2.5D coupled FE-BE methodology for the prediction of railway induced vibrations. Soil Dynamics and Earthquake Engineering, 30, pp. 1500-1512, 2010.

[14] Alves Costa, P., Calçada, R. \& Silva Cardoso, A., Track-ground vibrations induced by railway traffic: In-situ measurements and validation of a 2.5D FEM-BEM model. Soil Dynamics and Earthquake Engineering, 32(1), pp. 111-128, 2012.

[15] Colaço, A., Alves Costa, P. \& Connolly, D., The influence of train properties on railway ground vibrations. Structure and Infrastructure Engineering, 12(5), pp. 517534, 2016.

[16] Hall, L., Simulations and analyses of train-induced ground vibrations in finite element models. Soil Dynamics and Earthquake Engineering, 23(5), pp. 403-413, 2003. 
[17] Kouroussis, G., Gazetas, G., Anastasopoulos, I., Conti, C. \& Verlinden, O., Discrete modelling of vertical track-soil coupling for vehicle-track dynamics. Soil Dynamics and Earthquake Engineering, 31(12), pp. 1711-1723, 2011.

[18] Galvin, P., Romero, A. \& Domínguez, J., Fully three-dimensional analysis of highspeed train track soil-structure dynamic interaction. Journal of Sound and Vibration, 329(24), pp. 5147-5163, 2010.

[19] El Kacimi, A., Woodward, P.K., Laghrouche, O. \& Medero, G., Time domain 3D finite element modelling of train-induced vibration at high speed. Computers and Structures, 118, pp. 66-73, 2013.

[20] Kouroussis, G., Connolly, D.P., Vogiatzis, K. \& Verlinden, O., Modelling the environmental effects of railway vibrations from different types of rolling stock: A numerical study. Shock and Vibration, 2015.

[21] Arlaud, E., Costa D'Aguiar, S. \& Balmes, E., Validation of a reduced model of railway track allowing long 3D dynamic calculation of train-track interaction. Computer Methods and Recent Advances in Geomechanics - Proceedings of the 14th Int. Conference of International Association for Computer Methods and Recent Advances in Geomechanics, IACMAG 2014, (September), pp. 1193-1198, 2014.

[22] Kouroussis, G., Connolly, D., Olivier, B., Laghrouche, O. \& Alves Costa, P., Railway cuttings and embankments: Experimental and numerical studies of ground vibration. Science of the Total Environment, 557-558, pp. 110-122, 2016.

[23] Jones, C.J., Use of numerical models to determine the effectiveness of anti-vibration systems for railways. Proceedings of the Institution of Civil Engineers - Transport, 105(1), pp. 43-51, 1994.

[24] Jones, C.J.C. \& Block, J.R., Prediction of ground vibration from freight trains. Journal of Sound and Vibration, 193(1), pp. 205-213, 1996

[25] Steenbergen, M.J.M.M. \& Metrikine, A.V., The effect of the interface conditions on the dynamic response of a beam on a half-space to a moving load. European Journal of Mechanics, A/Solids, 26(1), pp. 33-54, 2007.

[26] Chen, Y., Wang, C.J., Chen, Y.P. \& Zhu, B., Characteristics of stresses and settlement of ground induced by train. Environmental Vibrations: Prediction, Monitoring, Mitigation and Evaluation: Proceedings of the International Symposium on Environmental Vibrations, pp. 33-42, 2015.

[27] Dong, K., Connolly D.P., Laghrouche, O., Woodward, P.K., Ho, C. \& Alves Costa, P., The effect of soil non-linearity on mixed traffic railway lines: Passenger vs Freight loads. GeoShanghai International Conference, Springer, pp. 227-236, 2018. 